\title{
Assessment of Sex-Specific Genetic and Environmental Effects on Bone Mineral Density
}

\author{
Lillian B. Brown, ${ }^{1}$ Elizabeth A. Streeten, ${ }^{2}$ Alan R. Shuldiner,${ }^{2,3}$ Laura A. Almasy, ${ }^{4}$ Patricia A. Peyser, ${ }^{1}$ \\ and Braxton D. Mitchell ${ }^{2 *}$ \\ ${ }^{1}$ Department of Epidemiology, University of Michigan School of Public Health, Ann Arbor, Michigan \\ ${ }^{2}$ Division of Endocrinology, Diabetes and Nutrition, University of Maryland School of Medicine, Baltimore, Maryland \\ ${ }^{3}$ Geriatric Research and Education Clinical Center (GRECC), Veterans Administration Medical Center, Baltimore, Maryland \\ ${ }^{4}$ Department of Genetics, Southwest Foundation for Biomedical Research, San Antonio, Texas
}

\begin{abstract}
Although it is widely accepted that genes contribute significantly to the variation in bone mineral density (BMD), the nature of the genetic contribution is poorly defined. There are large gender differences in BMD, although whether sex-specific genetic effects influencing variation in BMD contribute to these differences is not known. To address this issue, we studied 929 subjects from large families participating in the Amish Family Osteoporosis Study. Bone mineral density was measured at the hip and spine by dual energy x-ray absorptiometry (DXA). We used variance decomposition procedures to partition variation in BMD into genetic and environmental effects common to both sexes and to men and women separately. After accounting for covariate effects, the heritability of BMD ranged from 0.63 to 0.72 in men and 0.80 to 0.87 in women. The residual environmental variance in BMD at the spine, but not hip, was significantly higher in men than in women $(P<0.05)$, reflecting a greater variance in BMD due to unexplained non-genetic factors in men. In contrast, there were no significant differences between men and women in the magnitude of the genetic variance in BMD, nor did the genetic correlation in BMD between men and women differ significantly from one. Overall, these analyses do not provide evidence for sex-specific genetic effects, suggesting that many of the genes influencing variation in BMD should be detectable in both men and women. (c) 2004 Wiley-Liss, Inc.
\end{abstract}

Key words: sex; bone mineral density; genetics; variance; interaction; heritability

Grant sponsor: National Institutes of Health; Grant numbers: RO1-AR46838, RO1-AG18728, RO1-HL69313, and M01 RR165001 awarded to the University of Maryland General Clinical Research Center.

*Correspondence to: Braxton D. Mitchell, PhD, Division of Endocrinology, Diabetes and Nutrition, University of Maryland School of Medicine, 660 W. Redwood Street, Room 492, Baltimore, MD 21201. E-mail: bmitchel@medicine.umaryland.edu

Received 11 December 2003; Accepted 10 March 2004

Published online 14 May 2004 in Wiley InterScience (www.interscience.wiley.com)

DOI: $10.1002 /$ gepi.20009

\section{INTRODUCTION}

Osteoporosis is a debilitating disease characterized by low bone mineral density (BMD) that is associated with significant morbidity and mortality. According to the Third National Health and Nutrition Examination Survey (NHANES III), 50\% of U.S. women over age 50 have low bone mass and $20 \%$ of white postmenopausal women have osteoporosis at the femoral neck (hip) [Looker et al., 1997]. Osteoporotic fractures are one of the most common causes of disability and contributors to medical care costs in many regions of the world [Cummings and Melton, 2002]. Large prospective studies have shown that almost all types of fracture are increased in adults with low BMD [Cummings et al., 1993]. Fractures result in functional impairment, including impaired basic activities of daily living, subsequent nursing home care, the loss of ambulatory ability, and loss of the ability to live independently [Cummings and Melton, 2002; Gullberg et al., 1997].

Longitudinal, family, and twin studies suggest that variation in BMD is strongly influenced by genes. Women with a maternal history of hip fracture have lower BMD than women without a history of such fracture [Seeman et al., 1994] and are themselves twice as likely to suffer a hip fracture [Cummings et al., 1993; Zmuda et al., 1999]. BMD is highly correlated between twin pairs [Eisman, 1999; Christian et al., 1989; Pocock et al., 1987] and among related family members [Jouanny et al., 1995; Matkovic et al., 1990; Ferrari et al., 1998; Lutz, 1986; Seeman et al., 1989]. 
Overall, twin and family studies suggest that after considering covariates, $60-80 \%$ of variance in bone density measurement is genetically determined [Eisman, 1999; Krall and Dawson-Hughes, 1993; Prentice, 2001].

The nature of the genetic contribution to BMD is poorly defined. There are strong gender differences in BMD that contribute to a substantially higher fracture risk among women than men. Moreover, the gender differences are not constant across the age range as, for example, in the immediate post-menopausal period, when bone loss is accelerated in women as compared to men of the same age [Hunter and Sambrook, 2000]. Given the large genetic effects on BMD, it is possible that different (although overlapping) subsets of genes contribute to variation in BMD in men and women and/or that the genetic determinants of BMD may be modulated by sexspecific hormonal, environmental, and nutritional factors. Evidence for sex-specific genetic effects on $\mathrm{BMD}$, however, is scant. In the experimental mouse model, Orwoll et al. [2001] examined peak BMD in males and females from 18 different inbred recombinant strains and observed significant gender by strain interactions, with males having higher BMD than females in some strains, but lower in others. In subsequent quantitative trait linkage (QTL) analysis, these researchers then identified six distinct chromosomal regions linked to variation in BMD in male mice only, five regions linked in female mice only, and two linked regions that were shared between the genders [Orwoll et al., 2001]. Whether these QTLs will, in fact, turn out to have differential effects on BMD between male and female mice remains to be seen, as does their potential relevance to BMD in humans.

In humans, Naganathan and colleagues also provided evidence for the presence of sex-specific effects on BMD by showing that the correlations in BMD at the forearm and spine, as measured by ultrasound, were higher in same sex dizygotic (DZ) twin pairs than in opposite sex DZ twin pairs [Naganathan et al., 2002]. The intraclass correlation for the forearm BMD measurement was 0.40 in both female ( $n=265$ pairs) and male $(n=71$ pairs) DZ twin pairs, compared to 0.19 in opposite sex twin pairs ( $n=82$ pairs). Estimated correlations between female DZ twin pairs, male DZ twin pairs, and opposite sex DZ twin pairs at the spine were $0.38,0.56$, and 0.17 , respectively. Additionally, linkage studies carried out in at least two populations have reported stronger evidence for linkage to QTLs influencing BMD in one sex than in the other [Karasik et al., 2003; Kammerer et al., 2003] although these results are difficult to interpret since the hypothesis of sex-specific linkage was not formally tested. Aside from these few studies, the issue of sex-specific genetic effects has not been extensively addressed.

The goal of our study is to explore more fully potential sex-specific differences in the relative influence of genetic and environmental factors on BMD. To address this issue, we have analyzed data collected from 929 Amish individuals from large extended families. These families were recruited through the Amish Family Osteoporosis Study (AFOS), a study consisting of subjects enrolled from very large families from Lancaster County, Pennsylvania. Using variance decomposition procedures, we quantified genetic effects on BMD that are common to both sexes and to men and women separately. Specifically, we considered the following questions: (1) is the magnitude of the genetic variation larger in one sex than in the other?; (2) is the magnitude of the residual environmental variation larger in one sex than in the other?; and (3) is there evidence for sexspecific genetic effects on BMD (i.e., is there a subset of genes that influences variation in BMD in both sexes jointly and another subset of genes that influences variation in each sex separately)?

\section{METHODS}

\section{SUBJECTS AND MEASUREMENTS}

The AFOS began in 1997 with the goal of identifying the genetic determinants of osteoporosis. Individuals believed to be at risk for osteoporosis by virtue of their fracture history or prior bone density measurements were recruited into the study as index cases. These individuals were recruited by word-of-mouth, a community-wide mailing, advertisements in an Amish newspaper, or by referral from local physicians. The diagnosis of osteoporosis in these individuals was verified by measurement of BMD using dual energy x-ray absorptiometry (DXA). Individuals found to have a $\mathrm{T}$ score of -2.5 or less in either the hip or spine were designated as probands. We then invited the probands' spouses and all first-degree relatives aged 20 years and over to participate in the study. In addition, we recruited into the study the firstdegree relatives of any other examined individual (e.g., spouses) having a T score of -2.5 or lower at the spine or hip on our bone densitometry test. 
Between the initiation of recruitment in 1997 and January 2002, a total of 943 individuals were enrolled into the AFOS, including 57 probands and their relatives. Of those enrolled, complete information was obtained on 929 subjects, including 573 women and 356 men. Using the extensive genealogical records maintained on the Amish [Beiler, 1988; Agarwala et al., 1998, 2001], these individuals could be combined into a single 14-generation pedigree. Study participants were evaluated at the Amish Research Clinic in Strasburg, PA, by qualified nurses known to the participants. A medical interview included past medical history, family history of medical problems including fractures, and specific details regarding previous fractures, history of medication use, and menstrual and reproductive history for women. Height was measured using a stadiometer and weight was recorded with the participant in standard Amish clothing but without shoes. The mineral content at the lumbar spine and hip was measured by DEXA by a registered nurse certified in bone densitometry (Hologic 4500W, Hologic, Inc., Bedford, MA). BMD was determined by dividing the total bone mineral content ( $\mathrm{g}$ ) by the projected area of the region scanned $\left(\mathrm{cm}^{2}\right)$. For this report, we have restricted analysis of BMD to measures obtained at the spine, femoral neck, and total hip. Total hip BMD is defined as the sum of the bone mineral content at the femoral neck, trochanter, and intertrochanter sites divided by the total area of these three sites.

The protocol for the AFOS was approved by the Institutional Review Board at the University of Maryland. Informed consent was obtained from all subjects prior to participation.

\section{ANALYTICAL METHODS}

We carried out a series of statistical analyses using a full pedigree-based variance component approach for the purpose of partitioning variation in BMD into selected components [Almasy and Blangero, 1998]. In the basic model, the level of $\mathrm{BMD}, \mathrm{y}$, for individual $\mathrm{i}$ was modeled as $y_{i}=\mu+\sum \beta_{i} X_{i j}+g_{i}+e_{i}$, where $\mu$ is the mean BMD, $X_{i j}$ is the $j$-th covariate for the ith individual, $\beta_{j}$ is its regression coefficient, and $g_{i}$ and $e_{i}$ represent the random deviations from $\mu$ for individual $i$ that are attributable to additive genetic and residual error effects, respectively. The residual error component includes true random error, measurement error, and any non-additive genetic compo- nents. The effects of $g_{i}$ and $e_{i}$ are uncorrelated and normally distributed with mean zero and variances $\sigma_{\mathrm{g}}^{2}$ and $\sigma_{\mathrm{e}}^{2}$, respectively. The $\sigma_{\mathrm{e}}^{2}$ term can be considered the residual environmental variance, that is, the remaining environmental variance after accounting for the effects of measured covariates. Maximum likelihood methods were used to simultaneously estimate the mean and variances as well as the covariate and genetic effects. All models included the following covariates: age, age ${ }^{2}$, height, and BMI. These factors were selected as covariates because they were each independently associated with one or more BMD measures in a sex-specific preliminary analysis. The significance of particular components can be assessed by comparing the likelihood of a model with the component of interest estimated to the likelihood of a model in which the component effect is constrained to be zero. The full and restricted models are then compared by likelihood ratio test, which produces a test statistic that is asymptotically distributed as a $\chi^{2}$ distribution with the degrees of freedom equal to difference in number of parameters between the two models.

Using this variance component modeling approach, we then considered various hypotheses concerning the sex-specific variances in BMD. Our initial goal was to compare the genetic variance between the two sexes. We addressed this issue in two ways, first by comparing the "relative" proportion of the variance attributable to genetic effects in men and women separately and, second, by comparing the absolute magnitude of the genetic effect. The proportion of the total phenotypic variation in BMD that could be attributable to additive genetic effects $\left(\sigma_{\mathrm{g}}^{2} / \sigma_{\mathrm{p}}^{2}\right)$ corresponds to "narrow" sense heritability $\left(\mathrm{h}^{2}\right)$ since it reflects the degree of additive genetic variance only. We tested whether the heritabilities in BMD differed between men and women (i.e., $\mathrm{h}_{\text {men }}^{2}=\mathrm{h}_{\text {women }}^{2}$ ) by comparing the difference between the heritability estimates in the two sexes with the estimated variance of the difference.

Estimating the absolute magnitude of the genetic variance required a further partitioning of the variance. Following the approach of Blangero and colleagues, [Blangero, 1993; Martin et al., 2002b; Towne et al., 1993], we expanded the basic variance component model to allow the genetic variances in male and female BMD to differ when men and women were considered together. Briefly, the expected genetic covariance 
between a male and female relative pair is defined as:

$$
\operatorname{COV}(\mathrm{GM}, \mathrm{GF})=2 \Phi \rho_{\mathrm{G}} \times \sigma_{\mathrm{G}-\mathrm{M}} \times \sigma_{\mathrm{G}-\mathrm{F}}
$$

where $\Phi$ is the coefficient of kinship between the two individuals, $\rho_{\mathrm{G}}$ is the genetic correlation between the expressions of the trait in the two sexes, and $\sigma_{\mathrm{G}-\mathrm{M}}$ and $\sigma_{\mathrm{G}-\mathrm{F}}$ are the genetic standard deviations for men and women, respectively.

With the additional terms as defined above, we constructed a general model that partitioned variance in BMD into the following 13 terms: an overall mean scaled to the value in males, a coefficient corresponding to the effect of sex $\left(\beta_{\text {sex }}\right)$, coefficients for age and sex*age ( $\beta_{\text {age }}$ and $\left.\beta_{\text {age }}{ }^{\text {sex }}\right)$, coefficients for age ${ }^{2}$ and sex ${ }^{*}$ age $^{2}$ $\left(\beta_{\text {age }}^{2}\right.$ and $\beta_{\text {age }}^{2}{ }^{*}$ sex $)$, coefficients for height $\left(\beta_{\text {height }}\right)$, and body mass index $\left(\beta_{\mathrm{BMI}}\right)$, male and female genetic standard deviations $\left(\sigma_{\mathrm{G}-\mathrm{M}}\right.$ and $\left.\sigma_{\mathrm{G}-\mathrm{F}}\right)$, male and female residual environmental standard deviations $\left(\sigma_{\mathrm{E}-\mathrm{M}}\right.$ and $\left.\sigma_{\mathrm{E}-\mathrm{F}}\right)$, and the genetic correlation between males and females $\left(\rho_{\mathrm{G}}\right)$. Genetic correlations reflect the degree to which the genetic effect on BMD in men correlates with the genetic effect on BMD in women [Falconer and MacKay, 1994]. Interaction terms of sex with age and age ${ }^{2}$ were included because of the wellestablished differences between men and women in the relationship between age and BMD.

This expanded model allowed us to test several explicit hypotheses related to sex by gene interactions. First, we considered if the magnitude of the genetic effect was similar between the sexes by testing whether the genetic standard deviations were similar between men and women (i.e., $\mathrm{H}_{0}$ : $\sigma_{\mathrm{G}-\mathrm{M}}=\sigma_{\mathrm{G}-\mathrm{F}}$ ). Rejection of this hypothesis implies that genes account for a larger proportion of the variance in one sex than in the other. In similar fashion, we tested if the magnitude of the residual environmental effect was similar between the sexes (i.e., $\mathrm{H}_{0}: \sigma_{\mathrm{E}-\mathrm{M}}=\sigma_{\mathrm{E}-\mathrm{F}}$ ). The third hypothesis that we tested was whether the magnitude of the genetic correlation was significantly less than one (i.e., $\mathrm{H}_{0}: \rho_{\mathrm{G}}=1$ ). A genetic correlation between men and women that is significantly less than one implies that a different gene or suite of genes contributes to variance in BMD in men and women. If there is a sex $\times$ gene interaction, then the expectation is that $\rho_{\mathrm{G}}<1$ and $\sigma_{\mathrm{G}-\mathrm{M}} \neq \sigma_{\mathrm{G}-\mathrm{F}}$.

As before, significance testing was conducted using the likelihood ratio test. Specifically, we compared likelihoods between models in which values of $\sigma_{\mathrm{G}-\mathrm{M}}$ and $\sigma_{\mathrm{G}-\mathrm{F}}$ were allowed to differ (full model) and in which they were constrained to be the same (restricted model). Similarly, we compared the likelihood between a model in which $\rho_{\mathrm{G}}$ was estimated (full model) to that in which its value was constrained to be one (restricted model). When testing models for which the value of a particular parameter was constrained to a boundary value (e.g., $\rho_{\mathrm{G}}=1$ ), the $P$ value was based on a $\frac{1}{2}: \frac{1}{2}$ mixture of a $\chi_{1}^{2}$ distribution and a point mass at zero [Self and Liang, 1987].

\section{RESULTS}

Basic characteristics of the study population are shown in Table I. The mean age of the 356 men and 573 women was approximately 50 years. Men were on average four to five inches taller than women (mean \pm standard deviation; $67.2 \pm 2.7$ vs. $62.8 \pm 3.5 \mathrm{in}$.$) and 12 \mathrm{lbs}$ heavier (171.2 \pm 38.0 vs. $159.5 \pm 49.3 \mathrm{lbs})$. BMD measurements at the spine (L1-L4), femoral neck, and total femur were significantly higher in men compared to women ( $P=0.003$ at the spine; $P<0.001$ at the femoral neck and total hip). The overall (phenotypic) variance in BMD was also significantly greater in women than in men at all three BMD sites $(P<$ 0.001 by the Levene test for equality of variances).

The numbers of relative pairs, both same sex and total, who were phenotyped and included in the analyses are shown in Table II. The sample included 2,049 female-female pairs (212 motherdaughter, 548 sister-sister, 673 aunt-niece, and 616 first cousin pairs) and 838 male-male pairs (103 father-son, 263 brother-brother, 257 uncle-nephew, and 215 first cousin pairs). Overall, there were 2,887 same sex and 2,552 opposite sex relative pairs, for a total of 5,439 total relative pairs, including same sex and opposite sex pairs combined.

TABLE I. Characteristics (mean \pm SD) of Amish Family Osteoporosis Study participants

\begin{tabular}{lccc}
\hline Variable & Men $(\mathrm{n}=356)$ & Women $(\mathrm{n}=573)$ & $\begin{array}{c}\text { Age-adjusted } \\
P \text { value }\end{array}$ \\
\hline Age $(\mathrm{yrs})$ & $50.2 \pm 16.9$ & $50.1 \pm 24.6$ & 0.60 \\
Height $(\mathrm{in})$ & $67.2 \pm 2.7$ & $62.8 \pm 3.5$ & $<0.001$ \\
Weight $(\mathrm{lb})$ & $171.2 \pm 38.0$ & $159.5 \pm 49.3$ & $<0.001$ \\
BMI $\left(\mathrm{kg} / \mathrm{m}^{2}\right)$ & $26.8 \pm 6.2$ & $28.4 \pm 8.1$ & $<0.001$ \\
& & & \\
BMD $\left(\mathrm{g} / \mathrm{cm}^{2}\right)$ & & & 0.003 \\
Spine $(\mathrm{LI}-\mathrm{L} 4)$ & $0.964 \pm 0.165$ & $0.939 \pm 0.205$ & $<0.001$ \\
$\quad$ Femoral neck & $0.879 \pm 0.150$ & $0.836 \pm 0.184$ & $<0.001$ \\
\hline Total femur & $1.011 \pm 0.156$ & $0.922 \pm 0.196$ & \\
\hline
\end{tabular}


TABLE II. Number of relative pairs included in the sample of 939 Amish subjects

\begin{tabular}{|c|c|}
\hline Relative pair class & Number \\
\hline \multicolumn{2}{|l|}{ Parent-offspring } \\
\hline Mother-daughter & 212 \\
\hline Father-son & 103 \\
\hline All pairs ${ }^{a}$ & 575 \\
\hline \multicolumn{2}{|l|}{ Sibling-sibling } \\
\hline Sister-sister & 548 \\
\hline Brother-brother & 263 \\
\hline All pairs ${ }^{\mathrm{a}}$ & 1,439 \\
\hline \multicolumn{2}{|l|}{ Avuncular } \\
\hline Aunt-niece & 673 \\
\hline Uncle-nephew & 257 \\
\hline All pairs ${ }^{\frac{1}{2}}$ & 1,778 \\
\hline \multicolumn{2}{|c|}{ Cousin-cousin ( $1^{\text {st }}$ cousin only) } \\
\hline Female-female & 616 \\
\hline Male-male & 215 \\
\hline All pairs ${ }^{\mathrm{a}}$ & 1,647 \\
\hline \multicolumn{2}{|l|}{ Total numbers of pairs ${ }^{b}$} \\
\hline Female pairs & 2,049 \\
\hline Male pairs & 838 \\
\hline Total same sex pairs & 2,887 \\
\hline Total $^{\mathrm{a}}$ & 5,439 \\
\hline
\end{tabular}

The heritabilities of BMD at the spine, femoral neck, and total femur were estimated after accounting for the effects of the measured covariates age, age ${ }^{2}$, height, and BMI. The residual heritability of BMD ranged from 0.63 (spine) to 0.72 (total femur) in men and from 0.80 (femoral neck) to 0.87 (spine and total hip) in women. At each site, the estimated residual heritability in BMD was significantly larger in women than in men $(P<0.001$ at all sites) (data not shown).

To gain insights into the factors contributing to variation in BMD in men and women, we partitioned the total variance in BMD into components attributable to measured covariates (e.g., age, height, and BMI), the additive effects of genes, and to unmeasured, or residual, environmental factors. Results of these analyses are shown in Table III. In men, measured covariates accounted for very little $(6.3 \%)$ of the total variation in spine BMD, and from 18 to $24 \%$ of the variation in hip BMD. The additive effects of genes accounted for 51 to $59 \%$ of the total variation in $\mathrm{BMD}$, in contrast to the 63 to $72 \%$ of the residual variation in BMD as described above. Thus, $35 \%$ of the total variation in spine BMD in men could not be accounted for by genes or measured covariates. In contrast, in women, the measured covariates accounted for $32 \%$ of the total variation in spine BMD and 52 to $53 \%$ of the total variation in hip BMD. The additive effects of genes accounted for an additional $59 \%$ of the variation in spine BMD in women and 38 to $42 \%$ of the variation in hip BMD. Thus, only 6 to $9 \%$ of the total variation in BMD in women could not be accounted for by genes and/or measured covariates.

After estimating the proportion of the total phenotypic variation attributable to genetic and environmental effects in men and women, we next tested several additional hypotheses, including whether the magnitude of the genetic and environmental variances differed between men and women and whether the genetic correlation in BMD differed between men and women. To accomplish these goals, we performed a more complete partitioning of BMD into its constituent genetic and residual environmental components. In these analyses, we allowed the genetic and residual environmental variances in BMD between males and females to differ, and also estimated the genetic and residual environmental correlations in BMD between men and women. Results from the full model, in which all parameters were estimated, are shown in Table IV. Following estimation of the full set of model parameters, we performed a series of nested tests

TABLE III. Components of variance for bone mineral density (BMD)

\begin{tabular}{|c|c|c|c|c|c|c|}
\hline \multirow[b]{2}{*}{ BMD site } & \multicolumn{3}{|c|}{ Men $(n=356)$} & \multicolumn{3}{|c|}{ Women $(n=573)$} \\
\hline & Measured covariates $^{a}$ & Genetic $^{\mathrm{b}}$ & Residual environment & Measured covariates $^{\mathrm{a}}$ & Genetic $^{b}$ & Residual environment \\
\hline Spine & 0.063 & 0.590 & 0.347 & 0.325 & 0.591 & 0.084 \\
\hline Femoral neck & 0.235 & 0.513 & 0.252 & 0.531 & 0.378 & 0.091 \\
\hline Total femur & 0.182 & 0.592 & 0.226 & 0.517 & 0.421 & 0.062 \\
\hline
\end{tabular}

${ }^{a}$ Measured covariates include age, age ${ }^{2}$, height, and BMI.

${ }^{\mathrm{b}}$ Note that the genetic contribution to total phenotypic variation presented in this table differs from the heritability presented in the text, which is estimated as the genetic contribution to residual (not total) phenotypic variation once covariate effects are accounted for. 
TABLE IV. Model parameters estimated from variance partitioning of bone mineral density (BMD)

\begin{tabular}{lccc}
\hline Parameter & $\begin{array}{c}\text { Spine BMD } \\
(\times 10, \text { in } \\
\left.\mathrm{g} / \mathrm{cm}^{2}\right)\end{array}$ & $\begin{array}{c}\text { Neck BMD } \\
(\times 10, \text { in } \\
\left.\mathrm{g} / \mathrm{cm}^{2}\right)\end{array}$ & $\begin{array}{c}\text { Total Hip BMD } \\
(\times 10, \text { in } \\
\left.\mathrm{g} / \mathrm{cm}^{2}\right)\end{array}$ \\
\hline$\mu$ & 9.27 & 8.41 & 9.85 \\
$\beta$ (age) & -0.02 & -0.04 & -0.03 \\
$\beta($ sex $)$ & 0.24 & 0.03 & -0.51 \\
$\beta\left(\right.$ age* $^{*}$ sex $)$ & -0.03 & -0.01 & -0.01 \\
$\beta$ (age $\left.^{2}\right)$ & -0.001 & 0.001 & -0.004 \\
$\beta\left(\right.$ age $^{2 *}$ sex $)$ & -0.001 & -0.001 & -0.001 \\
$\beta($ height $)$ & 0.08 & 0.09 & 0.09 \\
$\beta(\mathrm{BMI})$ & 0.09 & 0.11 & 0.13 \\
$\sigma_{\mathrm{G}-\mathrm{M}}$ & 1.07 & 0.92 & 0.96 \\
$\sigma_{\mathrm{G}-\mathrm{F}}$ & 1.21 & 0.91 & 0.96 \\
$\sigma_{\mathrm{E}-\mathrm{M}}$ & 0.77 & 0.65 & 0.62 \\
$\sigma_{\mathrm{E}-\mathrm{F}}$ & 0.39 & 0.48 & 0.43 \\
$\rho_{\mathrm{G}}$ & 0.91 & 0.90 & 0.97 \\
& & & \\
LL & -593.86 & -438.17 & -442.87 \\
$($ full model $)$ & & &
\end{tabular}

Hypothesis 1:

$\mathrm{H}_{0}$ : genetic variance equal between the sexes

Parameterization: $\sigma_{\mathrm{G}-\mathrm{M}}=\sigma_{\mathrm{G}-\mathrm{F}}$

$\begin{array}{lccc}\text { LL } & -594.39 & -438.18 & -442.88 \\ \text { (nested model): } & & & \\ \chi_{1}^{2} & 1.06 & 0.01 & 0.02 \\ P & 0.30 & 0.91 & 0.89 \\ \text { Conclusion } & \text { Accept } \mathrm{H}_{0} & \text { Accept } \mathrm{H}_{0} & \text { Accept } \mathrm{H}_{0}\end{array}$

Hypothesis 2:

$\mathrm{H}_{0}$ : environmental variance equal between the sexes

Parameterization: $\sigma_{\mathrm{E}-\mathrm{M}}=\sigma_{\mathrm{E}-\mathrm{F}}$

$\begin{array}{lccc}\text { LL } & -595.84 & -438.84 & -443.68 \\ \text { (nested model): } & & & \\ \chi_{1}^{2} & 3.96 & 1.32 & 1.62 \\ P & 0.046 & 0.25 & 0.20 \\ \text { Conclusion: } & \text { Reject } \mathrm{H}_{0} & \text { Accept } \mathrm{H}_{0} & \text { Accept } \mathrm{H}_{0}\end{array}$

Hypothesis 3:

$\mathrm{H}_{0}$ : genetic correlation similar between males and females Parameterization: $\rho G=1$

\begin{tabular}{cccc} 
LL & -594.27 & -438.56 & -442.93 \\
(nested model): & & & \\
$\chi_{1}^{2}$ & 0.82 & 0.78 & 0.10 \\
$P$ & 0.18 & 0.19 & 0.38 \\
Conclusion & Accept $\mathrm{H}_{0}$ & Accept $\mathrm{H}_{0}$ & Accept $\mathrm{H}_{0}$ \\
\hline
\end{tabular}

${ }^{a}$ Model parameters: $\mu=$ mean BMD; $\beta=$ regression coefficients (for age, age* sex, age ${ }^{2}$, age ${ }^{2 *} \operatorname{sex}$, height, and body mass index); $\sigma_{\mathrm{G}-\mathrm{M}}=$ genetic $\mathrm{SD}$ in males; $\sigma_{\mathrm{G}-\mathrm{F}}=$ genetic $\mathrm{SD}$ in females; $\sigma_{\mathrm{E}-\mathrm{M}}=$ environmental $\mathrm{SD}$ in males; $\sigma_{\mathrm{E}-\mathrm{F}}=$ environmental $\mathrm{SD}$ in females; $\rho_{\mathrm{G}}=$ genetic correlation in $\mathrm{BMD}$ between men and women. $\mathrm{BMI}=$ body mass index; $\mathrm{BMD}=$ bone mineral density; $\mathrm{LL}=\log$-likelihood.

$P$ values for Hypothesis 3 based on a $\frac{1}{2} \cdot \frac{1}{2}$ mixture of a $\chi_{1}^{2}$ and a point mass of zero. in which we constrained values of selected parameters, which enabled us to test, first, whether the magnitude of the genetic variance in BMD differed between men and women; second, whether the magnitude of the residual environmental variance in BMD differed between men and women; and third, whether the genetic correlation in BMD between male and female relative pairs differed from one. With respect to the first hypothesis, we observed that the genetic SD did not differ significantly between men and women $\left(\sigma_{\mathrm{G}-\mathrm{M}}\right.$ vs. $\sigma_{\mathrm{G}-\mathrm{F}}$ : spine: 1.07 vs. 1.21 ; femoral neck: 0.92 vs. 0.91 ; total hip: 0.96 vs. $0.96 ; P>0.30$ for all). In contrast, we observed marginal evidence ( $P=0.046)$ for a larger residual environmental SD in men than in women for spine BMD (0.77 vs. 0.39), although not for BMD at either of the two hip sites. With respect to the third hypothesis, we observed that the genetic correlation between men and women did not differ significantly from one $\left(\rho_{\mathrm{G}}=0.91,0.90\right.$, and 0.97 for spine, femoral neck, and total hip). Thus, our analyses provided modest evidence for a sex by residual environment interaction at one of the BMD sites (spine), but no evidence for a gene by sex interaction. Nor was there evidence for sexspecific genetics effects on BMD.

\section{DISCUSSION}

The hypothesis that genetic and/or residual environmental effects on BMD might differ between men and women is motivated in part by the well-known gender differences that are observed in BMD. Typically, men have higher BMD than women, and women experience a significantly higher rate of bone loss around the time of menopause compared to men of similar age. There are many possible explanations for these sex differences, including the sex differences present in levels of androgens and estrogens, which are thought to influence bone development and/or decrease bone resorption [Vanderschueren and Bouillon, 1995; Gallagher, 2003]. Genes may potentially play a significant role in influencing variation in steroid production and regulation, including the changes in these processes that occur over time.

Evaluating the gender-specificity of genetic effects on BMD is not straightforward. Although the hypothesis that a particular allele is more strongly associated with BMD in one sex than the other is easily tested in the context of conventional 
genetic association studies, such analyses consider only the effect of an individual gene. Linkage studies conducted in both mice [Orwoll et al., 2001] and humans [Karasik et al., 2003; Kammerer et al., 2003] have revealed the presence of QTLs and/or regions of linkage that are more strongly linked in one sex than in the other, although none of these studies has explicitly tested whether evidence for linkage could be excluded in the other sex. To our knowledge, only one other study has formally sought to identify gender-specific genetic effects in humans, with these researchers inferring the presence of such effects on the basis that the correlation in BMD was significantly higher in same sex DZ twins than in opposite sex DZ twins [Naganathan et al., 2002]. However, these data are also consistent with several other interpretations, including the presence of a common environmental component that was more frequently shared among same sex compared to opposite sex twin pairs.

Interestingly, the Amish population does not appear to be at particularly high risk for fracture, and, in fact, rates of non-traumatic hip fracture are somewhat lower in the Amish than in their nonAmish counterparts, an observation consistent with mean BMD in the Amish also being slightly higher [Streeten et al., 2004]. Nevertheless, the unique attributes of the Old Order Amish (OOA) make this population an attractive one for attempting to dissect out the genetic contributions to phenotypic variation. Amish families typically tend to be very large, so that there are a large number of sibling relative pairs available for analysis. Moreover, the Amish have a strong interest in their genealogies, and accurate recordkeeping dating back many generations allows the large Amish families to be linked into a single pedigree. Finally, the relatively homogenous environment of the OOA may allow for a more clear elucidation of the genetic factors contributing to BMD.

Comparison of trait heritabilities between men and women, whether expressed as the contribution of genes to total trait variability or residual trait variability, provides only limited insight into possible gender differences in genetic effects. The reason for this is that heritabilities are proportions, and their values are influenced both by the magnitude of the genetic variance and the contribution of residual environmental factors to the total variance. We, thus, tested several additional hypotheses, including whether the magnitude of the genetic variance differed between men and women and whether the genetic correlation in BMD differed between men and women. The fact that the magnitude of the genetic standard deviation did not differ significantly between men and women indicates only that the contribution of genes to the variance in absolute terms is relatively similar between men and women in this study group; this test does not address whether it is the same gene or suite of genes that influences variation in BMD in both sexes. However, this latter possibility (i.e., that the same subset of genes influences variation in BMD in men as in women) is consistent with the finding that the estimated genetic correlation did not differ significantly from one.

Our results do not support the existence of sex-specific genetic effects on BMD. However, this conclusion does not preclude the possibility that there might be individual loci that have sex-specific effects on BMD; rather the net contribution of sex-specific genetic effects across all loci is likely to be small. Two additional caveats should be considered. First, this study population consists of families ascertained on probands with a history of hip fracture and/or osteoporosis. Thus, the mean BMD in the study population is slightly lower than what would have been observed in randomly ascertained families. However, how this selection scheme might impact detection of sex-specific genetic effects on BMD is unclear. A second, and perhaps more limiting, issue is that we have also pooled subjects across a wide range of ages for our analyses. While pooling subjects of different ages produces large numbers of same sex relative pairs suitable for analysis, this strategy may dilute sex-specific genetic and residual environmental effects whose expression is age-dependent. In this regard, a more comprehensive evaluation of this issue might include analysis of 20-40-year-old men and women in order to evaluate sex-specific genetic and environmental influences on acquisition of peak bone mass, or alternatively, to restrict analysis to postmenopausal women and older men to evaluate potential sex-specific genetic and environmental influences on bone loss. Unfortunately, our study sample was not sufficiently large to consider sexspecific analyses in young and old groups separately as there were only 120 males and 179 females aged 20-40 years and 102 males and 169 females aged 60 years and over. These totals provided an insufficient number of relative pairs in these strata to obtain the robust partitioning of 
the variances required to estimate sex-specific genetic effects.

Despite the unique ancestral history of the Amish and their relative protection against hip fracture, it seems reasonable to expect that the basic conclusions reached by this study pertaining to sex-specific genetic effects should be generalizable to other populations. The OOA in Lancaster County are descendents of migrants from Western Europe and are thus derived from the same overall gene pool as the overall U.S. and European Caucasian populations. Perhaps more importantly, the analytic approach we followed emphasizes the additive effects of genes. Although generalizability of these findings in the Amish would be limited if there were Amish-specific mutations in genes that had very large effects on $\mathrm{BMD}$, we are not aware that this is the case. In our initial survey we did, in fact, identify several individuals with very low BMD who upon subsequent evaluation were found to carry mutations in COL1A2, the gene encoding type 1 collagen alpha 2 and responsible for osteogenesis imperfecta. However, these individuals were excluded from the current analysis.

It is possible that there may be gender differences in genetic effects influencing other aspects of bone morphology not captured by BMD. Malefemale differences in a variety of indices related to hip geometry and structure have been reported [Beck et al., 1992; Kaptoge et al., 2003], many of which are also related to hip fracture independently of BMD [Gluer et al., 1994; Partanen et al., 2001; Beck et al., 1996; Karlsson et al., 1996]. Genetic influences on some of these measures have been reported [Jian et al., 2004; Liu et al., 2004; Koller et al., 2003], although the sexspecificity of these effects has not yet been investigated.

Detection and identification of sex-specific genetic effects when they exist is a worthwhile pursuit because such effects may provide important insights into disease etiology (e.g., genes expressed in only one sex or the other may operate on sex-specific risk factors) and also because appropriately modeling these effects should theoretically enhance our ability to identify the genes underlying them. For example, knowledge of sexspecific genetic effects may motivate one's choice of candidate genes, or improve ability to localize individual loci through linkage analysis by explicit modeling of sex-specific linkage components [Martin et al., 2002a]. The absence of evidence for sex-specific genetic effects on BMD in our study offers the hope that at least many of the loci influencing variation in BMD should be detectable in both men and women.

\section{ACKNOWLEDGMENTS}

We thank Drs. Richa Agarwala and Alejandro Schaffer for their assistance in pedigree construction using the Amish Genealogical Database. We also thank Dr. Holmes Morton and Caroline Morton for their support in establishing and maintaining ties with the Amish community. Finally, we gratefully acknowledge our Amish liaisons and field workers and the extraordinary cooperation and support of the Amish community without which these studies would not have been possible. This work was supported in part by the University of Maryland General Clinical Research Center, Grant M01 RR165001, General Clinical Research Centers Program, National Center for Research Resources (NCRR), NIH.

\section{REFERENCES}

Agarwala R, Biesecker LG, Hopkins KA, Francomano CA, Schäffer AA. 1998. Software for constructing and verifying pedigrees within large genealogies and an application to the Old Order Amish of Lancaster County. Genome Res 8:211-221.

Agarwala R, Schäffer AA, Tomlin JF. 2001. Towards a complete North American Anabaptist genealogy II: analysis of inbreeding. Hum Biol 73:533-545.

Almasy L, Blangero J. 1998. Multipoint quantitative-trait linkage analysis in general pedigrees. Am J Hum Genet 62:1198-1211.

Beck TJ, Ruff CB, Scott WW, Jr., Plato CC, Tobin JD, Quan CA. 1992. Sex differences in geometry of the femoral neck with aging: a structural analysis of bone mineral data. Calcif.Tissue Int 50:24-29.

Beck TJ, Ruff CB, Mourtada FA, Shaffer RA, Maxwell-Williams K, Kao GL, Sartoris DJ, Brodine S. 1996. Dual-energy X-ray absorptiometry derived structural geometry for stress fracture prediction in male U.S. Marine Corps recruits. J Bone Miner Res 11:645-653.

Beiler K. 1988. Fisher family history: descendants and history of Christian Fisher (1757-1838), 3rd ed. Lancaster, PA: Eby's Quality Printing.

Blangero J. 1993. Statistical genetic approaches to human adaptability. Hum Biol 65:941-966.

Christian JC, Yu PL, Slemenda CW, Johnston CC, Jr. 1989. Heritability of bone mass: a longitudinal study in aging male twins. Am J Hum Genet 44:429-433.

Cummings SR, Black DM, Nevitt MC, Browner W, Cauley J, Ensrud K, Genant HK, Palermo L, Scott J, Vogt TM. 1993. Bone density at various sites for prediction of hip fractures. The Study of Osteoporotic Fractures Research Group [see comments]. Lancet 341:72-75.

Cummings SR, Melton LJ. 2002. Epidemiology and outcomes of osteoporotic fractures. Lancet 359:1761-1767.

Eisman JA. 1999. Genetics of osteoporosis. Endocr Rev 20:788-804. 
Falconer D.S., MacKay T.F.C. 1994. Quantitative genetics, 4th ed. Essex, England: Longman Group Lmt.

Ferrari S, Rizzoli R, Slosman D, Bonjour JP. 1998. Familial resemblance for bone mineral mass is expressed before puberty. J Clin Endocrinol Metab 83:358-361.

Gallagher JC. 2003. Effect of estrogen on bone. In: Favus MJ, editor. Primer on the metabolic bone diseases and disorders of mineral metabolism, 5th ed. Washington, DC: American Society for Bone and Mineral Research. Chapter 53, p 327-330.

Gluer CC, Cummings SR, Pressman A, Li J, Gluer K, Faulkner KG, Grampp S, Genant HK. 1994. Prediction of hip fractures from pelvic radiographs: the study of osteoporotic fractures. The Study of Osteoporotic Fractures Research Group. J Bone Miner Res 9:671-677.

Gullberg B, Johnell O, Kanis JA. 1997. World-wide projections for hip fracture. Osteoporos Int 7:407-413.

Hunter DJ, Sambrook PN. 2000. Bone loss. Epidemiology of bone loss. Arthritis Res 2:441-445.

Jian WX, Long JR, Deng HW. 2004. High heritability of bone size at the hip and spine in Chinese. J Hum Genet 49:87-91.

Jouanny P, Guillemin F, Kuntz C, Jeandel C, Pourel J. 1995. Environmental and genetic factors affecting bone mass. Similarity of bone density among members of healthy families. Arthritis Rheum 38:61-67.

Kammerer CM, Schneider JL, Cole SA, Hixson JE, Samollow PB, O'Connell JR, Perez R, Dyer TD, Almasy L, Blangero J, Bauer RL, Mitchell BD. 2003. Quantitative trait loci on chromosomes $2 p, 4 p$, and $13 q$ influence bone mineral density of the forearm and hip in Mexican Americans. J Bone Miner Res 18:2245-2252.

Kaptoge S, Dalzell N, Loveridge N, Beck TJ, Khaw KT, Reeve J. 2003. Effects of gender, anthropometric variables, and aging on the evolution of hip strength in men and women aged over 65 . Bone 32:561-570.

Karasik D, Cupples LA, Hannan MT, Kiel DP. 2003. Age, gender, and body mass effects on quantitative trait loci for bone mineral density: the Framingham Study. Bone 33:308-316.

Karlsson KM, Sernbo I, Obrant KJ, Redlund-Johnell I, Johnell O. 1996. Femoral neck geometry and radiographic signs of osteoporosis as predictors of hip fracture. Bone 18:327-330.

Koller DL, White KE, Liu G, Hui SL, Conneally PM, Johnston CC, Econs MJ, Foroud T, Peacock M. 2003. Linkage of structure at the proximal femur to chromosomes 3, 7, 8, and 19. J Bone Miner Res 18:1057-1065.

Krall EA, Dawson-Hughes B. 1993. Heritable and life-style determinants of bone mineral density. J Bone Miner Res 8:1-9.

Liu PY, Qin YJ, Recker RR, Deng HW. 2004. Evidence for a major gene underlying bone size variation in the Chinese. Am J Human Biol 16:68-77.

Looker AC, Orwoll ES, Johnston CC, Jr., Lindsay RL, Wahner HW, Dunn WL, Calvo MS, Harris TB, Heyse SP. 1997. Prevalence of low femoral bone density in older U.S. adults from NHANES III. J Bone Miner Res 12:1761-1768.
Lutz J. 1986. Bone mineral, serum calcium, and dietary intakes of mother/daughter pairs. Am J Clin Nutr 44:99-106.

Martin LJ, Cole SA, Hixson JE, Mahaney MC, Czerwinski SA, Almasy L, Blangero J, Comuzzie AG. 2002a. Genotype by smoking interaction for leptin levels in the San Antonio Family Heart Study. Genet Epidemiol 22:105-115.

Martin LJ, Mahaney MC, Almasy L, MacCluer JW, Blangero J, Jaquish CE, Comuzzie AG. 2002b. Leptin's sexual dimorphism results from genotype by sex interactions mediated by testosterone. Obes Res 10:14-21.

Matkovic V, Fontana D, Tominac C, Goel P, Chesnut CH, III. 1990. Factors that influence peak bone mass formation: a study of calcium balance and the inheritance of bone mass in adolescent females. Am J Clin Nutr 52:878-888.

Naganathan V, Macgregor A, Snieder H, Nguyen T, Spector T, Sambrook P. 2002. Gender differences in the genetic factors responsible for variation in bone density and ultrasound. J Bone Miner Res 17:725-733.

Orwoll ES, Belknap JK, Klein RF. 2001. Gender specificity in the genetic determinants of peak bone mass. J Bone Miner Res 16:1962-1971.

Partanen J, Jamsa T, Jalovaara P. 2001. Influence of the upper femur and pelvic geometry on the risk and type of hip fractures. J Bone Miner Res 16:1540-1546.

Pocock NA, Eisman JA, Hopper JL, Yeates MG, Sambrook PN, Eberl S. 1987. Genetic determinants of bone mass in adults. A twin study. J Clin Invest 80:706-710.

Prentice A. 2001. The relative contribution of diet and genotype to bone development. Proc Nutr Soc 60:45-52.

Seeman E, Hopper JL, Bach LA, Cooper ME, Parkinson E, McKay J, Jerums G. 1989. Reduced bone mass in daughters of women with osteoporosis. N Engl J Med 320:554-558.

Seeman E, Tsalamandris C, Formica C, Hopper JL, McKay J. 1994. Reduced femoral neck bone density in the daughters of women with hip fractures: the role of low peak bone density in the pathogenesis of osteoporosis. J Bone Miner Res 9:739-743.

Self SG, Liang KY. 1987. Asymptotic properties of maximum likelihood estimators and likelihood ratio tests under nonstandard conditions. J Am Stat Assoc 82:605-610.

Streeten EA, McBride DJ, Lodge AL, Pollin TI, Stinchcomb DG, Agarwala R, Schaffer AA, Shapiro JR, Shuldiner AR, Mitchell BD. 2004. Reduced incidence of hip fracture in the Old Order Amish. J Bone Miner Res 19:308-313.

Towne B, Blangero J, Siervogel RM. 1993. Genotype by sex interaction in measures of lipids, lipoproteins, and apolipoproteins. Genet Epidemiol 10:611-616.

Vanderschueren D, Bouillon R. 1995. Androgens and bone. Calcif Tissue Int 56:341-346.

Zmuda JM, Cauley JA, Ferrell RE. 1999. Recent progress in understanding the genetic susceptibility to osteoporosis. Genet Epidemiol 16:356-367. 